\title{
LI. On a new method of obtaining pure silver, either in the metallic state or in the form of oxide
}

\author{
William Gregory M.D. F.R.S.E.
}

To cite this article: William Gregory M.D. F.R.S.E. (1843) LI. On a new method of obtaining pure silver, either in the metallic state or in the form of oxide , Philosophical Magazine Series 3, 22:145, 283-286, DOI: 10.1080/14786444308636381

To link to this article: http://dx.doi.org/10.1080/14786444308636381

Published online: 01 Jun 2009.

Submit your article to this journal $\sqsubset$

Џ Article views: 2

Q View related articles $\square$ 
lime were exactly the same as those of ordinary pyrogallic acid. It is evident, therefore, that pyrogallic acid does not combine with ammonia, but is slightly oxidized when brought in contact with it.

The addition of a little potash also rendered solutions of pyrogallic acid alkaline and even darker coloured than ammonia does. The coloration takes place first at the surface of the liquid, and is evidently the effect of oxidation. When evaporated in vacuo it became a black gummy mass, which showed no disposition to crystallize. When this black mass was dissolved in water, in which it is very soluble, and treated with sulphuric acid, it effervesced, apparently from the escape of carbonic acid. It also gave off the vapours of acetic acid in abundance. These were easily recognisable by their smell, and by their immediately reddening litmus paper when held over them. When the solution was very concentrated, a little of a dark brown matter precipitated; but if the solution was at all dilute no precipitate appeared. I made an unsuccessful attempt to collect this precipitate on a filter, and to free it from adhering sulphuric acid by washing it with cold water. The whole of the black matter was speedily dissolved and passed through the filter. Soda produced similar effects on pyrogallic acid. It is plain, therefore, that pyrogallic acid is decomposed by the alkalies, but does not combine with them, and that its acid properties, if indeed it possesses any, are very feeble. In this and some other respects it closely resembles pyromeconic acid.

When pyrogallic acid is dropped into acetate of copper, it causes a dark brown precipitate, which however quickly becomes black, and is very soluble. When we attempt to collect it on a filter and to wash it, the greater portion of the salt is dissolved by the water. The liquid when it first passes through the filter is colourless, but on standing a few minutes it becomes dark brown and slowly deposits a new precipitate. The compound first formed appears to be decomposed by the water.

When pyrogallic acid is added to a solution of bichromate of potash, it immediately turns it yellowish brown, and then dark brown till the liquid is almost opake, but no precipitate falls.

LI. On a ners Method of obtaining pure Silver, either in the Metallic State or in the form of Oxide. By William GreGORY, M.D., F.R.S.E., Member of the Chemical Society, \&c.*

THE chemist, as well as the metallurgist, has frequent oc1 casion to purify silver, especially from copper, which is dissolved along with it by nitric acid, the proper solvent of * Communieated by the Chemical Society; having been read $\mathrm{Fe}$ bruary $7,1843$. 
silver. By converting the silver into the insoluble chloride, it is effectually purified from copper as well as from all other metals, the chlorides of which are soluble. But here the difficulty begins : the chloride of silver is a very unmanageable product, at least in the moist way. It is true that if placed in water acidulated with hydrochloric acid, in contact with zinc or iron, the chloride of silver is reduced. But the process is tedious, seldom complete, and in the end unsatisfactory; for some zinc adheres to the reduced silver, so that it is not removed by digestion with moderately strong hydrochloric acid. This is proved by the action of ammonia, which extracts a good deal of oxide of zinc. Moreover, the zinc or iron is hardly ever pure; and its impurities, arsenic, carbon, and perhaps also copper and tin, remain with the silver. I have never got from silver thus reduced, a colourless solution of nitrate.

It is no doubt better to decompose the dried chloride of silver by the action of carbonate of potash or soda at a red heat. But although the silver is thus obtained pure, the process requires much experience and dexterity. If the heat be too low, the reduced silver is disseminated in small globules through the mass; if too high, the alkali corrodes the crucible rapidly, and the contents fall into the fireplace or ash-pit. There is often also a portion of silver cast up by the effervescence on the sides of the crucible, in small globules, which do not readily run down into the fused mass below. In short, this process, always ticklish, often fails. It is therefore desirable, if possible, to dispense with a furnace heat.

The method of reducing the silver from the impure nitrate by protosulphate of iron does not answer. It is long ere the action is terminated, and besides, some sulphate is always formed, which is not reduced, and is partly precipitated with the metal, and partly retained in solution.

The only remaining method, known to me, is that of reducing the silver from the impure (cupreous) nitrate or sulphate, by means of copper. The chief objection to this method is that it is somewhat tedious; but it is also not improbable that a trace of copper may adhere to the silver, chemically combined, as is the case to a large extent with mercury in the Arbor Diance. At least I have generally found copper in the silver I have thus prepared.

Considering these things, it appeared desirable to have once more recourse to the chloride, which can be easily obtained perfectly pure, and to decompose it without the contact of any reguline metal. The most obvious plan was to try the action of caustic alkalies in the moist way, and although it has been singularly enough hitherto overlooked, 1 find that caustic potash may be used with complete success. Diluted 
potash, or even a concentrated solution, if cold, has no apparent action on chloride of silver; and this, I presume, explains how the reaction about to be described has not been noticed. But a solution of potash, spec. grav. 1.25 to 1.30 , with the aid of heat, decomposes almost instantaneously the moist chloride of silver, converting it into a heavy, fine jet-black powder, which is pure oxide of silver. This oxide dissolves without the smallest residue, and without effervescence in diluted nitric acid, and yields a colourless and pure nitrate. The heat of the spirit-lamp reduces the oxide to a coherent spongy mass of absolutely pure silver.

The following method appears to me the most advantageous.

The cupreous solution of silver is precipitated by common salt, while hot, and the chloride of silver well washed by decantation with hot water. It should also be broken down with a spatula of platinum or a glass rod, during the washing, but not ground in a mortar, which causes it to cake, and impedes the action of the potash. The chloride, rohile still moist, is covered to about half an inch with a solution of caustic potash, spec. grav. 1.25 at least, and then boiled. During the boiling, which is best performed in a capsule of clean iron, silver or platinum, the chloride is to be well stirred, in order to bruise all curdy or lumpy particles. In five or ten minutes the powder has become black. If a small portion, taken out and washed, do not dissolve without residue in dilute nitric acid, the potash is to be decanted off, and the powder, still moist, is to be well rubbed down in a mortar, which may now be done with advantage. It is then returned into the capsule, and again boiled for five minutes with the same, or with fresh potash. It will now dissolve entirely in nitric acid; but if not, a second grinding will infallibly succeed. It is now only necessary to wash the oxide, which is completed by decantâtion in a few minutes, as the powder, from its great density, sinks at once to the bottom. The first two or three washings are made with hot water, the remainder with cold water; for when the oxide is nearly washed, it rises partially to the surface, with hot water, and thus a loss is occasioned in decanting. Of course, the whole washings (except the first, owing to the strength of the potash) may be conducted on a filter. But the powder is so fine, that probably a good deal would adhere to the paper when dry.

This oxide of silver appears in a form quite distinct from that of the oxide precipitated by potash from the nitrates, and is hitherto undescribed. It is very dense, homogeneous, and has a pure black colour, which has, if anything, a tint of blue; whereas the common oxide is bulky, far less dense, and of a grayish brown colour. 'They appear, however, to be chemi- 
cally identical. Not having a microscope, I have not studied their physical characters minutely; but I suspect, from its aspect in the liquid in which it is formed, that the new oxide is crystalline.

It is obvious that the above process furnishes an easy method of procuring a very pure oxide of silver, and of course the action of heat gives us the silver in the state of metal. It is, I conceive, applicable both to the manufacture of nitrate (in a state of absolute purity) and to the metallurgic process for obtaining pure silver. For both objects, it is a matter of no consequence, if some chloride should have escaped the action of the alkali. This chloride is left undissolved by the nitric acid, and is separated by filtration; while if the oxide (not quite free from chloride) be mixed with a little nitre or carbonate of potash, and fused, the whole silver is obtained with the utmost facility*. In order to give an idea of the ease with which the whole is performed, I may mention that I dissolved a half-crown, and obtained the whole of the silver it contained, within a very trifling fraction (chiefly decanted in the first washing of the chloride, but not lost), by the above process, within two hours, in a fused state. The silver was quite pure. There is no doubt that to chemists also an easy method of obtaining quickly pure oxide of silver, in a form much less hygrometric than the usual one, will be acceptable.

It is particularly to be noticed, that if the chloride have ONCE BEEN DRIED, it is with great difficulty decomposed, even by a long boiling with potash.

King's College, Aberdeen, Jan. 20, 1843.

LII. Observations on M. Reiset's Remarks on the new Method for the Estimation of Nitrogen in Organic Com" pounds, and also on the supposed part which the Nitrogen of the Atmosphere plays in the formation of Ammonia. By H. WILL, Ph. D.†.

THE method for the estimation of the nitrogen in organic substances described by Varrentrapp and myself $\neq$ has been received by many chemists with the greatest approbation, as well on account of its simplicity as the accuracy and security with which results can be obtained. M. Reiset has however

* In fact, this process, imperfectly pefformed, is an excellent preliminary step, when a large quantity of chloride is to be reduced. The impure oxide requires so little alkali to complete its decomposition, that the crucible runs no risk. A little borax nay be added as a flux.

+ Communicated by the Chemical Society; having been read March 2I, 1843.

$\$$ Annal. der Chemie, b. xxxix. s. 257. See also Philosophical Magazine for March 1842, p. 2l6. 